\title{
CONVENCIONES PROBATORIAS Y LA NECESIDAD DE SU APLICACIÓN EN LA ETAPA DE JUZGAMIENTO REALIZARLO ES UNA BUENA PRÁCTICA JUDICIAL
}

\author{
CARLOSGERMÁNGUTIÉRREZGUTIÉRREZ*
}

\begin{abstract}
Resumen
Aunque nuestro código procesal peruano no regula las convenciones probatorias en la etapa de juzgamiento, el autor manifiesta que existen circunstancias que justifican su aplicación en dicha etapa, como son: el desconocimiento de la teoría del caso, el consentimiento del acusado, el no vulnerar el debate probatorio, el cambio de "hecho notorio" por "hecho no controvertido", así como simplificación y celeridad del juzgamiento. Explica tres casos concretos en donde se formularon convenciones probatorias en la epata de juzgamiento, concluyendo que a pesar de que no existe norma expresa que permita su aplicación, tampoco existe incompatibilidad para aceptar aquellas convenciones probatorias que no hayan sido promovidas anteriormente por las partes, por lo que propone una modificación legislativa.
\end{abstract}

Palabras clave: Convenciones probatorias, etapa de juzgamiento.

\begin{abstract}
Although our peruvian procedural code does not regulate the evidentiary conventions at the trial stage, the author states that circumstances exist and justify its application at that stage , as they are: the lack of knowledge of theory of the case, the consent of the accused, not violate the probative discussion , the change of " notorious fact " for " undisputed fact", as well as simplification and the speed of trial. It explains three specific cases where evidentiary conventions were formulated at the stage of trial , concluding that although there is no express provision which allows implementation, neither exists compatibility in order to accept those evidentiary conventions which have not been previously promoted by the legal parties, therefore it proposes a legislative amendment.
\end{abstract}

Keywords: Evidentiary conventions, trial stage.

\section{Sumario}

1.- Antecedentes. 1.1.- Regulación actual. 1.2.- Sobre su escasa aplicación en la etapa intermedia. 2.- Planteamiento del problema. 3. Hipótesis.- 4. -

* Juez titular del Primer Juzgado Penal Colegiado Supraprovincial de Trujillo, exfiscal provincial penal titular del Distrito Fiscal de Piura. 
Definiciones. 5.- La justificación de su aplicación en la etapa de juzgamiento. 5.1.- El desconocimiento de la teoría del caso. 5.2.- El consentimiento del acusado. 5.3.- No vulnera el debate probatorio. 5.4.- El cambio de "hecho notorio" por "hecho no controvertido". 5.5.- No es incompatible, ni extingue su utilización en la etapa intermedia. 5.6.- Simplificación y celeridad de juzgamiento. 6.- Casuística de aplicación de convenciones probatorias en la etapa de juzgamiento. 7. -Observaciones finales. 8.- Conclusiones. 9.Sugerencias.

\section{Antecedentes}

\subsection{Regulación actual}

Algunos consideran que las convenciones probatorias son un instituto; otros, una herramienta, un mecanismo o una expresión de la justicia penal, que surge en el contexto de las negociaciones y acuerdos que las partes realizan dentro de un proceso con las características actuales de oralidad, contradictorio y público.

En nuestra normativa procesal penal peruana, las convenciones probatorias están reguladas en lo que corresponde a la segunda etapa del proceso común, denominada etapa intermedia y se presentan luego que el Ministerio Público ha formulado el requerimiento acusatorio conforme al Art. $349^{\circ}$ del Nuevo Código Procesal Penal (en adelante NCPP). Es decir, los sujetos procesales dentro de los 10 días posteriores al requerimiento (Art. 350.2 ${ }^{\circ}$ NCPP) y por escrito podrán proponer acuerdos, esto es, convenciones probatorias sobre hechos, circunstancias y medios de prueba que acepten; los cuales, en caso se aprueben por el juez de investigación preparatoria, se darán por acreditados, obviando su actuación probatoria en el juicio.

Normativamente y de manera dispersa las convenciones probatorias aparecen en el Art. $156.3^{\circ}$ del NCPP (sobre lo que es objeto de prueba), propiamente en el Art. $350.2^{\circ}$ (respecto a su oportunidad de presentación por escrito), asimismo en el Art. $352.6^{\circ}$ (de las decisiones adoptadas en la audiencia preliminar) y finalmente en el Art. 353.2c del NCPP (respecto al auto de enjuiciamiento en el que se detallará en el caso que sea aprobado). Teniendo en cuenta lo anterior, en nuestro nuevo código procesal peruano, no existe dispositivo legal alguno que regule las convenciones probatorias en la etapa de juzgamiento. 
Si bien existen trabajos de investigación sobre las convenciones probatorias desarrollados a nivel nacional tanto en artículos individuales como en tratados, aquellos concuerdan con el aspecto normativo regulado y desarrollado en la etapa intermedia y bajo la competencia del juez de investigación preparatoria y excepcionalmente por el juez de juzgamiento en caso de un reexamen cuando el primero no aprobó el acuerdo.

El presente artículo pretende que la comunidad jurídica, conozca la utilidad de la aplicación de las convenciones probatorias en la etapa de juzgamiento, y que además constituyen una buena práctica procesal; toda vez que así lo consideramos los jueces del Primer Juzgado Penal Colegiado de Trujillo. En ese sentido, el presente artículo desarrollará la oportunidad de formular convenciones probatorias a nivel de juzgamiento, las circunstancias que justifican el ser aceptadas en juicio oral y su forma de promoción; ya que en la etapa intermedia por las razones que se detallarán no lo hicieron; y así como, a manera de ejemplos se presentarán casos reales donde se les aplicó, siendo aprobadas las convenciones probatorias dentro del respeto de los derechos de las partes y los principios garantistas del proceso penal actual.

\subsection{Sobre su escasa aplicación en la etapa intermedia}

No obstante, cuando la regulación de este mecanismo procesal se encuentra dentro de las disposiciones de la etapa intermedia teniendo por finalidad facilitar -teóricamente- el juicio oral, en la realidad resulta escasa su aplicación. Al respecto en el 2010 AGUIRRE $\mathrm{CH}^{1}{ }^{1}$ puso en conocimiento que realizó una encuesta contando con un universo de 18 personas en la que participaron 07 fiscales, 05 abogados y 06 jueces de diversos distritos judiciales como son: Arequipa, Huaura, Huaral, La Libertad, Lambayeque, Lima, Moquegua, Piura Tacna y Cuzco. El resultado de su trabajo de investigación ${ }^{2}$ arrojó que 06 de los encuestados (03 abogados y 03 fiscales) realizaron alguna convención probatoria; asimismo 02 abogados y 04 fiscales manifestaron no haber tenido experiencia con la figura procesal aludida; en tanto que los jueces manifestaron no haber participado, ni aprobado alguna convención probatoria presentada por las partes; los demás resultados también interesantes obran en el texto completo antes indicado.

1 AGUIRRE, Javier. (2015). Convenciones Probatorias. Su aplicación en el Perú. Un estudio dogmáticoempírico, en

http://www.incipp.org.pe/media/uploads/documentos/convenciones_probatorias.pdf, consulta: 25 de marzo del 2015, p. 17.

2 AGUIRRE, Javier. (2015). Op. cit., p.20. 
Asimismo, el presente tiene como fuente directa de información aproximadamente 300 casos de juzgamiento ${ }^{3}$ conocidos por el Primer Juzgado Penal Colegiado de Trujillo (competente para juzgar delitos cuya pena mínima prevista por la ley es superior a los 6 años de pena privativa de libertad ${ }^{4}$ ), desde julio del 2013 hasta diciembre del 2014, periodo en el cual no se ha conocido de la existencia de convenciones probatorias aprobadas o desestimadas por los Jueces de Investigación Preparatoria. Se corrobora además que la escasa aplicación de las convenciones probatorias en la etapa intermedia se debe a lo que AGUIRRE $\mathrm{CH}^{5}$ fundamenta como: el desconocimiento de las convenciones probatorias como figura procesal, el momento inadecuado para su postulación, el plazo insuficiente, su presentación por escrito, la cultura de confrontación entre abogados y fiscales y el rol pasivo del juez de investigación preparatoria para no promoverlas en la etapa intermedia. Sin embargo buena parte de dichos problemas pueden ser superados con una actitud proactiva del juez y la participación de la partes en la etapa de juzgamiento, como se demostrará en el presente trabajo.

\section{Planteamiento del problema}

¿Existen circunstancias que justifican la aplicación de convenciones probatorias en la etapa de juzgamiento?

\section{Hipótesis}

Si existen circunstancias que justifican la aplicación de convenciones probatorias dentro de la Etapa de Juzgamiento.

\section{Definiciones}

El maestro ROSAS YATACO 6 señala que convenciones probatorias son el arreglo que realizan las partes del proceso penal en el sentido de dar por confirmados ciertos hechos sobre los cuales no exista discusión respecto de su ocurrencia y las circunstancias que los rodean, y que

3 Oficina de Administración del Módulo Penal de Trujillo de la Corte Superior de Justicia de La Libertad-Perú.

4 Código Procesal Penal (D. Legislativo N ${ }^{\circ}$ 957) Artículo $28^{\circ}$ Competencia material y funcional de los Juzgados Penales: 1. Los Juzgados Penales Colegiados, integrados por tres jueces, conocerán materialmente de los delitos que tengan señalados en la Ley, en su extremo mínimo, una pena privativa de libertad mayor de seis años.

5 AGUIRRE, Javier. (2015). Op. cit., p. 20.

6 Rosas, Jorge. (2013). Tratado de Derecho Procesal Penal - Análisis y desarrollo de las instituciones del nuevo Código Procesal Penal. Volumen II, Pacífico Editores, 2013, p. 951. 
debido a ello, no podrán ser discutidos ni debatidos en el juzgamiento.

GUERRERO PERALTA ${ }^{7}$, considera a las estipulaciones probatorias como una manifestación de consenso interpartes que son permitidas en el proceso penal y hacen parte de una serie de institutos probatorios en los que se asume un pactum sin necesidad de prueba y de las cuales hacen parte, la admisión de hechos y las presunciones.

Para AGUIRRE $\mathrm{CH}^{8}{ }^{8}$ las convenciones probatorias son una de las tantas expresiones de la justicia negociada, propia del sistema acusatorio inspirador de la reforma procesal penal en América Latina.

COCIÑA CHOLAKY ${ }^{9}$ señala que la legislación nacional de Chile concibe a las convenciones probatorias como una herramienta que permite al juez de garantía, si existiere consenso entre los intervinientes, sustraer del periodo probatorio determinados enunciados. Asimismo, citando a RODRIGO CERNA y MARÍA INÉS HORVITZ, expresa que las convenciones probatorias son acuerdos adoptados en la audiencia de preparación del juicio oral por el fiscal con el imputado, autorizados por el juez de garantía, destinados a dar por aceptados determinados hechos con el fin de no ser objeto de discusión en el juicio oral.

$\mathrm{Al}$ respecto PABLO TALAVERA ${ }^{10}$ señala que una excepción al principio de necesidad de prueba está constituida por las llamadas convenciones probatorias. Las convenciones probatorias o estipulaciones de prueba son acuerdos celebrados entre el fiscal y la defensa para tener por probados alguno o algunos hechos o circunstancias, así como sobre los medios de prueba que deban ser utilizados para probar determinados hechos y considera que es una expresión más de un modelo adversativo, en el cual las partes tienen una mayor presencia e intervención.

7 Citado por Rosas, Jorge (2013). Op. cit., p. 952.

8 AGUIRRE, Javier. (2015). Op. cit., p. 4.

9 CociÑA, Martina. (2013). La dinámica entre la búsqueda de la verdad y las convenciones probatorias en el proceso penal, en "Revista de Estudios de la Justicia. Chile", $N^{\circ} 18$, p. 144, http://web.derecho.uchile.cl/cej/rej18/COCINA_11.pdf, consulta: 25 de marzo del 2015.

10 TALAVERA, Pablo. (2009). La Prueba en el Nuevo Proceso Penal. Manual del derecho Probatorio de la Valoración de las Pruebas en el proceso penal común. Lima: AMAG - Cooperación Alemana al desarrollo-GTZ, p.59. 


\section{La justificación de su aplicación en la etapa de juzgamiento}

Es razonablemente necesario al amparo del principio de economía y celeridad procesal que las partes puedan tener la posibilidad de celebrar convenciones probatorias en la etapa de Juzgamiento ante el juez de su competencia, manteniendo su finalidad; esto es, que se tenga por acreditado el hecho o circunstancia, obviando desde luego su actuación probatoria o de ser el caso el establecimiento del acuerdo respecto al medio de prueba. $\mathrm{Si}$ bien de conformidad con el Art. 350.2 del NCPP, es de competencia del Juez de Investigación Preparatoria, considero que no hay imposibilidad material para que también las partes puedan acordar y promoverlas ante el Juez de Juzgamiento. En ese sentido, existen circunstancias que justifican su aplicación de ser el caso durante la etapa de juzgamiento y que a continuación paso a fundamentar:

\subsection{El desconocimiento de la teoría del caso}

En principio, la escasa realización de convenciones probatorias en la etapa intermedia, como lo advierte AGUIRRE $\mathrm{CH}^{11}$ es porque la Defensa no ha hecho pública su teoría del caso, lo cual coloca en una situación de desventaja a la Fiscalía y asimismo, es porque la acusación escrita no necesariamente supone la teoría del caso fiscal, ya que pueda dar posibilidad a una recalificación o establecer calificaciones alternativas o subsidiarias. Por ende, las mejores condiciones entre las partes procesales para celebrar un acuerdo de esta naturaleza, son luego de la audiencia preliminar, mejor aún, si es después de haber las partes conocido los alegatos de apertura en la audiencia de juzgamiento.

UGAZ ZEGARRA ${ }^{12}$, concluye que se debe implementar en nuestra legislación procesal penal, la figura jurídica del descubrimiento de pruebas obligatorio o Discovery norteamericano como presupuesto indispensable para que las partes procesales puedan iniciar adecuadamente una convención probatoria. Consecuentemente, en tanto no se encuentre implementada una figura procesal similar al Discovery norteamericano ${ }^{13}$ en nuestra norma procesal

11 AGUIRRE, Javier. (2015). p. 22.

12 UGAZ, Ángel. (2015). La convención Probatoria. ¿Negociando a ciegas? La importancia del Acuerdo de Descubrimiento de pruebas, como presupuesto de las Convenciones Probatorias., en http://www.mpfn.gob.pe/escuela/contenido/actividades/docs/2241_4_doc4.pdf, Consultado: 25 de marzo del 2015, p. 41.

13 La figura del Discovery norteamericano, a decir de AGUIRRE Javier. (2015). cit. "consiste básicamente en la recolección de evidencias que realiza Fiscalía a fin de desvirtuar la presunción de inocencia del acusado; y si bien no está obligado a recabar evidencia liberadora 
penal para aplicar adecuadamente una convención probatoria en la etapa intermedia -independiente de la estrategia técnica de las partes procesalessiempre en el plano de la realidad práctica será un hecho el desconocimiento de la teoría del caso por parte de los sujetos procesales y en consecuencia la escasa realización de convenciones probatorias en la etapa intermedia.

Teniendo en cuenta que el conocimiento de las teorías del caso de la fiscalía y de la defensa es develado al inicio de la etapa de juzgamiento, considero que el Juez de Juzgamiento al preguntar a las partes procesales si están en la posibilidad de asumir convenciones probatorias, respecto de hechos o medios de prueba -sin que ello signifique que sea el juez quien las señale, ni las establezca, sino tan solo interrogar si están en condiciones de formular entre si acuerdos en atención a sus estrategias o teorías planteadas-, realizar aquella pregunta de parte del órgano jurisdiccional no significa contaminación, ni adelantamiento de juicio. Así, son las partes quienes deberán establecer si consideran estratégico llegar a una acuerdo probatorio y centrarse en lo que queda de las audiencias en lo necesario para el debate probatorio, esto es, el examen y contraexamen de sus órganos de prueba o la oralización de documentos relacionados con temas controvertidos; y así cumplir los principios de libertad probatoria, necesidad de la prueba, así como el juzgar con celeridad y economía procesal.

\subsection{El consentimiento del acusado}

Según nuestra normatividad procesal penal (Art. 351.1 del NCPP) no es obligatoria la presencia del acusado en la audiencia preliminar de control de acusación, pero resulta indispensable su presencia para que en un supuesto caso de asumir convenciones probatorias, sea el acusado, quien de su conformidad, ello resulta evidentemente contradictorio. Otra circunstancia es que cuando no concurre la defensa del acusado a dicha audiencia, entonces el Juzgado convoca a un Defensor público, que en la mayoría de los casos no ha conferenciado con el acusado; peor aún, si no ha rendido una declaración durante las diligencias preliminares o investigación preparatoria. Entonces, si por imposibilidad material, la Defensa nunca ha conferenciado con el acusado por estar ausente o contumaz, la pregunta sería ¿Podría el abogado defensor asumir una convención probatoria con la Fiscalía sin

de responsabilidad penal, si está obligado a ponerla a disposición de la Defensa en caso de encontrarlas. Asimismo dicha obligación alcanza a la Defensa en caso encuentre medios de prueba de cargo, durante la etapa de investigación, toda vez que ninguna de las partes está autorizada a guardar secretos a la parte contendiente a menos que lo respalde en su derecho a no auto incriminarse". 
autorización o consentimiento del acusado? consideramos que no; sin embargo, algunos podrían responder afirmativamente, en el sentido que sería una estrategia técnica de la Defensa, convenir sobre hechos o medios de prueba. No obstante, debe tenerse en cuenta que el acusado una vez presente en el juicio oral podría desconocer u oponerse a dicha convención (oposición que sería amparada), más aún, si es el acusado sobre quién recae los resultados y consecuencias de un juzgamiento.

Asumo, que es derecho del acusado tener conocimiento de los elementos de convicción y los medios de prueba que conforman la acusación fiscal, y que por ello no es posible que la Defensa (pública o particular) sin la presencia del acusado pueda asumir convenciones probatorias, toda vez que no se encuentra respaldada por su aceptación o conformidad; circunstancia que REYNA ALFARO ${ }^{14}$ denomina como expresiones del derecho de defensa del acusado en su vertiente de defensa material. En similar sentido, UGAZ ZEGARRA considera que en las convenciones probatorias debe observarse el consentimiento del acusado de formar parte de las mismas, ya que un vicio de estas características puede invalidar el acuerdo en el momento del examen que realiza el juzgador ${ }^{15}$.

Si la presencia física del acusado es obligatoria en las fases del juzgamiento, entonces la norma procesal penal debe posibilitar que las partes procesales puedan realizar convenciones probatorias y además puedan ser aprobadas por el Juez de Juzgamiento, ya sea al inicio, durante o al final de la etapa del juzgamiento, tal como se ejemplifica en tópico 6 del presente artículo.

\subsection{No vulnera el debate probatorio}

COCIÑA CHOLAKY ${ }^{16}$ argumenta que la aplicación de una convención probatoria en el proceso, constituye la renuncia de la verdad constatada; es decir, los intervinientes (sujetos procesales) no están constatando algo externo material, sino construyendo idealmente una verdad, a partir de lo que convienen como tal y que en ese sentido apartarían la verificación de lo real a lo concertado; además, que independientemente si lo pactado o no se ajusta al supuesto normativo, subsiste el peligro si lo pactado establece en el proceso penal, una decisión alejada de la verdad.

ReYNA, Luis. (2015). Mamual de Derecho Procesal Penal. Lima: Instituto Pacífico, p. 236.

15 UGAZ, Ángel. (2015). Op. cit., p. 09.

16 CociÑA, Martina. (2013). Op. cit.. p. 157. 
Respecto a ello, no es que mediante la aprobación de una convención probatoria se crea una verdad de la nada, sino que los términos de la convención deberán estar sustentados en los actos de investigación que se han realizado o recabado durante la investigación preparatoria o diligencias preliminares. Dichos actos de investigación han sido puestos en conocimiento a las partes procesales en la etapa intermedia bajo el mecanismo que UGAZ ZEGARRA ${ }^{17}$, llama descubrimiento con negociación o sin negociación. Es preciso señalar que el término descubrimiento que utiliza el citado autor ${ }^{18}$ puede resultar extraño para algunos operadores; pero en este punto se está refiriendo al descubrimiento obligatorio de pruebas realizados por Fiscalía.

Promover convenciones probatorias entonces en las fases del juzgamiento no vulnera el debate probatorio y tampoco perjudica a las partes procesales, ya que son ellas quienes analizarán qué hechos, circunstancias o qué medios de prueba consideran que serán susceptibles de un acuerdo. Como se ha dicho, ello no significa contaminación del juez de juzgamiento que las promueva, ni un adelantamiento de juicio, toda vez que aún no ha emitido un pronunciamiento sobre el fondo, sino tan solo se evita que el juzgamiento de dilate innecesariamente.

\subsection{El cambio de "hecho notorio" por "hecho no controvertido"}

La convención probatoria, como se ha dicho, debe estar sustentada en los actos de investigación realizados en el proceso y en ese sentido si no existieran hechos, circunstancias o puntos controvertidos; entonces no habría necesidad de debate ni tampoco la materialización del derecho de contradicción en el juzgamiento. La norma adjetiva señala en el Art. 156.3 del

17 UGAZ, Ángel. (2015). Op. cit.. p. 9.

18 Recuérdese que la Fiscalía está obligada a poner en conocimiento de las partes, todo lo actuado, salvo las excepciones establecidos por la ley procesal durante la etapa de investigación preparatoria. Este descubrimiento, entonces está representado en el acceso de las partes procesales a la carpeta fiscal que contiene todos los actos de investigación, realizados para cada caso concreto. No obstante, es necesario precisar además que en nuestro sistema procesal penal la Defensa no está obligada al descubrimiento de pruebas, ni existe norma alguna que le sea obligatoria, salvo que se trate de una negociación informal, como por ejemplo las negociaciones informales para efectos de una terminación anticipada. En nuestro sistema procesal penal todos los actos de investigación fiscal tanto de cargo como de descargo y lo que las partes propongan, se desarrollan en la carpeta fiscal. Por su parte, la defensa no puede realizar una investigación paralela, ya que en nuestra normativa procesal penal los actos de investigación que desea realizar, deben ser canalizados por el despacho fiscal; así por ejemplo: las declaraciones juradas ante notario conteniendo declaraciones de testigos o conteniendo retractaciones de agraviados no son considerados actos de investigación y menos viable su actuación en juicio, como tal. 
NCPP respecto al objeto de prueba que si las partes lo acuerdan se le tendrá y se valorará como "hecho notorio"; tal calificación de hecho notorio considero que no es la más idónea, sino que más bien debería detallarse como texto normativo la siguiente afirmación: se valorará como "hecho no controvertido".

Lo notorio conforme lo desarrolla el maestro ROSAS YATACO ${ }^{19}$ son los hechos que, por su general y pública aceptación, no pueden ser ignorados. Aquellos que entran naturalmente en el conocimiento, en la cultura o en la información normal de las personas, con relación a un lugar o a un determinado grupo social y a un momento determinado. En suma, los hechos notorios no exigen ser probados, por cuanto se trata de hechos públicos que son conocidos por el grupo social o en su gran mayoría, siendo de una comprensión para cualquier persona de modo elemental.

Además señala MIXÁN MASS20 algunos elementos constitutivos del concepto de notoriedad:

a) El hecho, suceso o cualidad, debe ser real e indiscutible.

b) El conocimiento generalizado sobre aquel, generalidad que incluye al director de la investigación o al juzgador como uno de los conocedores de lo notorio.

Que ese conocimiento generalizado este vigente durante la época de la investigación o del juzgamiento y que sea capaz de generar certeza sobre la realidad de aquello que es notorio.

Por lo antes anotado considero que una convención probatoria no reúne las calidades ni características de un hecho notorio propiamente dicho, porque su objeto no reviste ni asimila dichas condiciones. Si lo que pretende la norma, es que se tenga por cierto lo que han convenido las partes, mejor sería señalar que el juez lo valorará como un hecho no controvertido y aceptado por las partes, sin cuestionamiento alguno. Téngase en cuenta que la decisión que se adoptará al final del juzgamiento será la de valoración conjunta de toda la actividad probatoria desarrollada en el juzgamiento y en la cual deberán tener una especial consideración las convenciones probatorias. Finalmente esta anotación da a lugar a sugerir una modificación del texto

19 Rosas, Jorge. (2013). Op. Cit., p. 834.

20 MiXán MASs. Cuestiones epistemológicas y teoría de la investigación y de la prueba, p. 244, citado por Rosas Jorge (2013). Op. cit., p. 834. 
normativo actual, esto es, de sustituir "como hecho notorio" por la expresión "como hecho no controvertido".

\subsection{No es incompatible, ni extingue su utilización en la etapa intermedia}

No debe entenderse que si se regula textualmente en la norma procesal penal la facultad de los jueces de juzgamiento de consultar a las partes si existe posibilidad de arribar a una convención probatoria, ello extinguiría o sería incompatible con la posibilidad de presentar las convenciones probatorias en el marco del Art. 350 del NCPP. Por el contrario, considero que ofrece una pauta normativa de la actividad del juez proactiva como preparación para el debate en juicio, claro está, después de los alegatos de apertura, o después de la admisión de nuevos medios de prueba de ser el caso e incluso si las partes lo piden hasta antes de la finalización de la actividad probatoria. Es decir, la convención probatoria podría arribarse al inicio, durante la fase probatoria o hasta antes que culmine el juzgamiento.

En efecto, si una norma autoriza incorporar esta nueva oportunidad de tramitación, ello sería facultad de las partes para solicitarlas cuando lo crean conveniente, y en relación a sus intereses, lo cual redundará en beneficio de una celeridad procesal y en un juzgamiento en la menor cantidad de sesiones de audiencia, evitando las sesiones innecesarias.

\subsection{Simplificación y celeridad del juzgamiento}

Existen instituciones, herramientas procesales, procesos especiales y mecanismos procesales ${ }^{21}$ que están a disposición de las partes procesales para promover una simplificación procesal como son, por ejemplo: el principio de oportunidad, los acuerdos reparatorios, la confesión propiamente dicha, el proceso inmediato, la terminación y conclusión anticipada y las convenciones probatorias; cada uno de estos con sus peculiaridades, presupuestos y preclusión aplicativa $a^{22}$.

Hace varios años atrás, recuerdo, que el principio de oportunidad no se aplicaba a pesar que se encontraba regulado expresamente en la normativa procesal penal. Posterior a ello, diversas tesis, artículos y libros promovieron

21 GUTIÉRREZ, Carlos. (2013). La optimización de la gestión fiscal con la debida implementación de mecanismos procesales, en "Revista Actualidad Jurídica", Gaceta Jurídica, Lima, № 235, Junio 2013, pp. $106-111$.

22 CAmpos Hidalgo, Faviola, expresión "preclusión aplicativa" en su ponencia "Medidas de coerción Procesal". Colegio de abogados de Piura, Junio, 2013. 
su aplicación y desde el 2004 hasta la fecha, se ha constituido en la salida alternativa ${ }^{23}$ de mayor aplicación en lo que concierne a la descarga procesal. Algo similar ocurre en el caso de las convenciones probatorias, pues como ya se viene mencionando, no se promueven ni se aplican en la realidad, y menos en las cantidades que se esperaban.

Es de conocimiento de todos los operadores de justicia que las sesiones de audiencia para casos de mediana y alta criminalidad involucran la concurrencia de un número considerable de órganos de prueba, así como de abundante documentales, lo cual por cierto, da lugar a que el tiempo utilizado sea muy extenso. Ello, obviamente implica diversas problemáticas:

a) Reprogramaciones de audiencia sin sentido.

b) La no concurrencia de testigos y peritos al juicio oral.

c) A veces reprogramaciones de audiencia por inasistencia del Fiscal.

d) Reprogramaciones por inasistencia de uno $u$ otro abogado, peor cuando son una pluralidad de abogados.

e) El reemplazo de un abogado particular por un defensor público, peor cuándo este último no llega preparado para el interrogatorio.

f) El cambio repentino de abogados particulares, o provocadas incidencias para cansar a los órganos de prueba de cargo.

Estas circunstancias que bien podrían, desde una perspectiva de lealtad al proceso penal, verse aligeradas y superadas en parte, si se promoviera, utilizara, aceptara y aprobara, el mecanismo procesal de las convenciones probatorias en la etapa de juzgamiento. No se está pretendiendo ni siquiera que las partes procesales se releven del derecho legítimo que les asiste, en caso de la Fiscalía de actuar los medios de prueba de cargo, del acusado a su defensa material ${ }^{24}$ o de la defensa técnica para ofrecer medios de prueba de descargo y el derecho de contradicción ${ }^{25}$. Así por ejemplo en un caso de tráfico ilícito de drogas, no resultaría razonable citar a juicio al perito químico de la ciudad de Lima (Laboratorio Central de Criminalística de la Policía Nacional del Perú - Lima) que elaboró el dictamen pericial químico de droga a una audiencia de instalación de juzgamiento en la ciudad de Trujillo del Distrito Judicial de La Libertad, si no va a ser interrogado por la defensa del acusado, toda vez que no cuestiona el peso ni la calidad de la droga y ni siquiera los procedimientos periciales químicos. Me pregunto entonces,

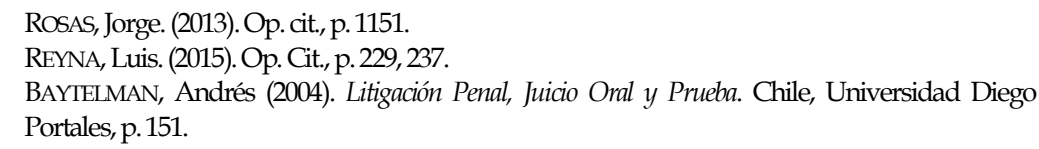


porque no promoverlo en la etapa de juzgamiento luego de escuchar los alegatos de inicio. Más bien, lo que debe evitarse es la formalidad inoficiosa ante los principios reguladores de un juzgamiento con prontitud en el contexto de un debido proceso para las partes.

\section{Casuística de aplicación de convenciones probatorias en la etapa de juzgamiento}

A manera de ejemplo, los siguientes son dos casos reales en los que el Primer Juzgado Penal Colegiado Supraprovincial de Trujillo preguntó a las partes si existía la posibilidad de alguna convención probatoria en atención a sus teorías del caso y que no dieron lugar a ningún acuerdo entre ellas:

- $\quad$ Exp. 4456-2014-35. Referente al delito de robo agravado ${ }^{26}$ :

Escuchados los alegatos de apertura de ambas partes, en sesión de juzgamiento de fecha 24/09/14, el Juzgado preguntó a las partes si arriban a convenciones probatorias; la Fiscalía propuso a la defensa una convención probatoria respecto al contenido del certificado médico legal practicado al Imputado con motivo de su intervención policial; sin embargo, la Defensa manifestó que era necesario ser examinado por el médico legista.

En la siguiente audiencia de fecha 17/10/2014 concurrió el perito médico, al ser interrogado primero por la Fiscalía respecto a la pericia, declaró que el acusado presentaba lesiones traumáticas recientes de origen contuso con una atención facultativa de 01 día por 05 días de incapacidad médico legal, así como lo referido por el acusado en la data de la pericia, esto es, que mientras viajaba en una moto, que le habían quitado a una persona; junto a dos amigos es detenido por efectivos de Serenazgo, quienes le suben a la fuerza a la camioneta y le trasladan a la comisaria de Chao y que no recibió ningún maltrato psicológico.

Habiendo finalizado Fiscalía correspondía el contra interrogatorio por parte de la Defensa, toda vez que en la anterior sesión de audiencia había señalado que era necesario el examen del Perito en juicio; sin embargo, lo anecdótico

26 Los alegatos de apertura fueron los siguientes: La Fiscalía: Sostuvo que el día 28 de setiembre de 2013 a las 13:00 horas, dos sujetos le propusieron al acusado, sustraer una moto y por ello recibiría S/. 300 nuevos soles. Divisaron una moto, el acusado actuó como campana, el sujeto conocido como "Beny" amenaza al agraviado y este le da la llave. Abordaron la moto lineal y huyeron hasta Chao. El agraviado puso en conocimiento de la policía, este hecho, al sentirse atrapados huyeron por las plantaciones y solo pudieron atrapar al acusado y a un menor de edad. La Defensa: Sostuvo que su patrocinado es inocente, que no existe medio de prueba idónea, que fue intervenido con la moto, pero luego de los hechos. 
del caso, es que la Defensa dijo que no formularía ninguna pregunta. La pregunta es ¿acaso hubiese sido mejor una convención probatoria respecto a los términos del certificado médico legal? Al final del caso de la valoración de toda la prueba actuada, el acusado fue condenado a doce años de pena privativa de libertad por el delito imputado.

- Exp. 1294-2014-16. En la causa penal referente al delito de actos contra al pudor de menor ${ }^{27}$ :

En sesión de juzgamiento de fecha 03/10/14, el Juzgado después de haber oído las teorías del caso de las partes procesales, y no habiendo ofrecimiento de nuevos medios de prueba ${ }^{28}$, se procedió con el examen del acusado y antes de finalizar la sesión se preguntó si realizarían convenciones probatorias, ambas partes señalaron que lo precisaran en la próxima audiencia.

En la siguiente sesión, la Defensa manifestó que ha conferenciado con el acusado, que replanteará su tesis de defensa aceptando los cargos y la responsabilidad penal.

Ante ello Juzgado resolvió la nulidad de los alegatos de apertura de la defensa para que los reformule, lo que dio lugar a que el acusado acepte los cargos en su contra, consecuentemente, se dispuso la conclusión anticipada de juicio, aprobándose el acuerdo respecto a la pena y reparación civil.

De otro lado, presento como ejemplo tres casos concretos en que se preguntó a las partes, lo que dio lugar a que estas formularan convenciones

27 Alegato de apertura de Fiscalía: el padre de la agraviada denunció que el día 27/02/2014 en el interior de su domicilio al promediar las 13:30 horas cuando se encontraba reunido con su conviviente se les acercó su sobrina diciendo que fue testigo que el dueño de la casa, el acusado, la había estado besando y realizando tocamientos en el cuerpo y partes íntimas a su hija; posteriormente al tomar conocimiento de lo sucedido, el denunciante se llevó a su menor hija hacia una parte a fin de que le cuente todo, habiéndole manifestado la menor que luego de salir del baño vio al acusado que estaba recostado sobre una cama y este la llamó, para luego jalarla hacia él y comenzar a darle besos en la boca, mientras le tocaba su cuerpo, habiendo la menor llamado a su madre a fin de evitar que sigan los actos.

28 Artículo $373^{\circ} \mathrm{NCPP}$ Solicitud de nueva prueba. 1. Culminado el trámite anterior, si se dispone la continuación del juicio, las partes pueden ofrecer nuevos medios de prueba. solo se admitirán aquellos que las partes han tenido conocimiento con posterioridad a la audiencia de control de la acusación. 2. Excepcionalmente, las partes podrán reiterar el ofrecimiento de medios de prueba inadmitidos en la audiencia de control, para lo cual se requiere especial argumentación de las partes. El Juez decidirá en ese mismo acto, previo traslado del pedido a las demás partes.3. La resolución no es recurrible. 
probatorias las cuales fueron aceptadas y consecuentemente sin objeto el examen de órganos de prueba:

- $\quad$ Exp. 1831-2014-14. referente a los delitos de robo agravado y lesiones graves seguido contra el acusado J.A.S.R. en agravio de A.L.R.R. ${ }^{29}$ :

En sesión de juzgamiento del 24/09/14, escuchados los alegatos de apertura de ambas partes, Fiscalía invocando el principio de oralidad ${ }^{30}$ propuso convenir sobre los hechos de las lesiones y el certificado médico legal practicado al agraviado, toda vez que defensa del acusado manifestó que su defendido acepta la comisión del delito de lesiones graves. El Juzgado emite resolución aprobando la convención probatoria arribada por las partes en el proceso, respecto al contenido del certificado médico legal 1181-B; el mismo cuyo contenido se tiene por cierto y en consecuencia careciendo de objeto el examen del Perito Médico Legal que lo elaboró.

Al finalizar la actividad probatoria y valorada la prueba actuada el acusado fue absuelto por el delito de robo agravado; pero fue condenado por el delito de lesiones graves tipificado en el Art. $121^{\circ} \mathrm{del}$ Código Penal.

De otro lado, presento como ejemplo tres casos concretos en que se preguntó a las partes, lo que dio lugar a que estas formularan convenciones probatorias las cuales fueron aceptadas y consecuentemente sin objeto el examen de órganos de prueba:

- $\quad$ Exp. 702-14-3. referente al delito de robo agravado seguido contra los acusados M.A.A.V. y J.A.U.A. en agravio de C.C.Ch. ${ }^{31}$ :

29 Exp. 1831-2014-14, los alegatos de apertura fueron: Por la fiscalía Que el día 19 de agosto del 2013 siendo las 19:00 horas el agraviado estaba en su vehículo Station Wagon de placa rodaje SGN-303 por la Calle Huanchaco en Casagrande, es abordado por dos sujetos, siendo que el acusado sube adelante y lo coge del cuello y con un cuchillo le golpea el rostro y cuerpo, el otro le rebusca sustrayéndole S/. 50.00 nuevos soles y sus lentes. Por la Defensa: Que el acusado no le ha sustraído nada, tan solo ha sido una pelea en que fue agredido y se defendió.

30 "La oralidad es una herramienta importante dentro del proceso acusatorio pues es el medio que se emplea para que discurran las afirmaciones de las partes. Como instrumento de comunicación, busca hacer viva la actuación de la prueba y hace que la inmediación tenga sentido. Además, busca minimizar el uso de la escritura, sin eliminarla totalmente". Así en: ARBULÚ, Víctor. (2014). La Investigación Preparatoria en el nuevo proceso penal, en "Actualidad Penal", Instituto Pacífico, Lima, p. 20.

31 Exp. 702-14-3 los alegatos de apertura fueron: Por la Fiscalía: Que el 04 de febrero del 2014, siendo 12:45 horas, efectivos policiales patrullaban por la Calle Inca Roca en Río Seco y los pobladores le hacen indicación que por la calle Wiracocha, habían asaltado, se dirigen por esa 
En sesión de juzgamiento del 03/10/14, luego de escuchados los alegatos de apertura y no habiendo admisión de nuevos medios de prueba, el Juzgado preguntó a la partes si respecto a los hechos o medios probatorios admitidos en la etapa intermedia existía la posibilidad de alguna convención probatoria. Ante ello las partes refieren que formulan convención probatoria respecto de la Pericia de Balística Forense 147-2014 cuyo contenido se refiere a las armas de fuego incautadas, su idoneidad y operatividad. El Juzgado emite resolución aprobando la convención probatoria arribada por las partes en el proceso, respecto al contenido de la Pericia de Balística; el mismo cuyo contenido es aceptado por las partes sin controversia ni cuestionamiento alguno y tiene por cierto careciendo de objeto el examen del Perito que lo elaboró.

Al final de las demás sesiones de audiencia y luego de la valoración de toda la prueba actuada los acusados fueron absueltos del delito de robo agravado.

- Exp. 6331-13-50. referente al delito de robo agravado seguido contra C.A.V.C. en agravio de I.J.C.C y R.S.C.C.32:

calle y por el parque Jana ven a cuatro sujetos corriendo, los intervienen a dos (Jhampiers y Miguel), se encuentra por el parque una mochila, un cargador de celular Nokia, audífonos y a un costado de la mochila un arma calibre 12 hechiza adaptada y luego por el interior del parque encuentra otra arma calibre 38 abastecida con seis cartuchos sin percutir, los llevan a comisaría donde estaba el agraviado colocando denuncia y reconoce a los intervenidos como los que lo asaltaron a las 12:49 horas, cuando iba en la camioneta de placa rodaje C4A-764 con su esposa, lo asaltan uno lo agarra con arma y otro le quila la mochila con objetos y su celular de marca Nokia, el que le quita la mochila fue Jhampiers y el otro fue Miguel, por lo que los hechos se encontrarían encuadrados en el tipo penal establecido en los artículo $188^{\circ}$ y $189^{\circ}$ incisos 3 y 4 del Código Penal, siendo que los bienes fueron recuperados a excepción del celular. Por la Defensa: Que el 04 de febrero del 2014 estaban comiendo y luego pasan por el cementerio, ven personas corriendo y cuando escuchan balazos, corren a su domicilio siendo intervenidos a cincuenta metros del parque, la mochila aparece en el parque, a ellos no se les encuentra nada, tampoco arma alguna, en juicio se desvirtuará la declaración de agraviados, la denuncia la hacen luego de tres horas de la intervención, invoca que son inocentes, por lo que pide absolución.

32 Exp. 6331-13-50, la fiscalía ofreció acreditar robo agravado: Que el día 02 de diciembre del año 2013 al promediar las 00:15 horas de la madrugada los agraviados Irving y Robin fueron a la discoteca Zona Vip permanecieron hasta las 01:20 horas, luego salieron de dicho lugar, en ese momento Irving entregó a su hermano Robín su billetera conteniendo S/.400.00 nuevos soles y se dirigieron a tomar un taxi y en circunstancias que estaban caminando se acercaron seis sujetos y uno lo amenazó diciéndole ya perdiste carajo dame el dinero y le metió la mano a su bolsillo, quitándole ambas billeteras agrediéndoles para ello y luego fugaron, a los pocos minutos llegaron a la zona dos vehículos de Serenazgo y tenían a un intervenido que era el imputado, con sus pertenencias; reconociéndole el agraviado como la persona que le quitó las 
La partes luego de dos sesiones de juzgamiento el 03/10/14 arribaron a una convención consistente en que aceptan por cierto que al momento que se intervino al acusado se le encontró en su poder una billetera del agraviado conteniendo tarjetas del banco BCP y dinero de propiedad del agraviado conforme se detalla en la Acta de Intervención Policial, acuerdan que con el acta de intervención dan por cierto el hecho y consideran sin objeto que concurran el personal de seguridad ciudadana J.A.V.B. y A.R.A.T. que participaron en el acta de intervención del acusado. Siendo aprobado en esos términos.

El acusado luego de las sesiones de juzgamiento y actuada toda las actividad probatoria y con la recalificación ${ }^{33}$ por hurto agravado formulado por fiscalía, el acusado fue condenado por este delito.

- Exp. 3627-2013-65. referente al delito de tráfico ilícito de drogas seguido contra S.V.G.A. y J.E.B.B. en agravio del Estado:

A iniciativa de las partes luego de dos sesiones de juzgamiento, el 03/10/14 formularon convención probatoria respecto del Dictamen Pericial de Química (Droga) No 7313-2013 elaborado por el perito del laboratorio Central de Criminalística PNP - Lima, respecto de la muestra consistente en 10 cascarones de huevos que en su interior contenía bolsas de plástico incoloro con sustancia blanco pardusca pulverulenta que concluye positivo para pasta básica de cocaína con un peso bruto de $0.238 \mathrm{Kg}$. Además sobre el Examen Toxicológico Na $735-$ 2013 realizado al acusado S.V.G.A., toda vez que no existe controversia en el resultado que concluye negativo para consumo de drogas.

billeteras a su hermano Robín y quién lo golpeó en el rostro. Posteriormente Fiscalía atribuye una tipificación alternativa de hurto agravado en grado de tentativa en razón que durante la investigación preparatoria se dispuso la ampliación testimonial de ambos agraviados sosteniendo que el día de los hechos se encontraba junto a su hermano, salieron de tomar unas cervezas del Bar Kanos, siendo que en dichas circunstancias cruzaron la avenida, un sujeto se acercó por detrás, sustrajo su billetera y se corrió. La Defensa señaló en sus alegatos de apertura: Que no se podrá acreditar el robo agravado, que el hecho fue un hurto agravado, que los testigos acreditarán que la violencia no la produjo el acusado.

33 Artículo $374^{\circ}$ Poder del Tribunal y Facultad del Fiscal.- 1 . Si en el curso del juicio, antes de la culminación de la actividad probatoria, el Juez Penal observa la posibilidad de una calificación jurídica de los hechos objeto del debate que no ha sido considerada por el Ministerio Público, deberá advertir al Fiscal y al imputado sobre esa posibilidad. Las partes se pronunciarán expresamente sobre la tesis planteada por el Juez Penal y, en su caso, propondrán la prueba necesaria que corresponda. $\mathrm{Si}$ alguna de las partes anuncia que no está preparada para pronunciarse sobre ella, el Juez Penal suspenderá el Juicio hasta por cinco días, para dar oportunidad a que exponga lo conveniente. 
Luego de varias sesiones de juzgamiento y actuada toda la actividad probatoria, por el delito de tráfico ilícito de drogas el acusado J.E.B.B. fue absuelto de la acusación fiscal, en tanto el acusado S.V.G.A. fue condenado por el delito imputado.

\section{Observaciones finales}

Considero que el juez de juzgamiento está en condiciones de preguntar si existe algún acuerdo o convención probatoria o si existe la intención de llegar a un acuerdo, siempre que dicho acuerdo no sea constitutivo de responsabilidad penal, ni de antijuricidad, menos de culpabilidad; además si el juez pregunta a las partes ello no vulnera principio alguno ni las perjudica, ya que son ellas quienes analizarán y determinarán que hechos o que medios de prueba serán sujetos a convenciones probatorias en atención a sus estrategias.

En las convenciones probatorias no se debe entender que gana uno y pierde la otra parte, sino que ganan las dos partes o en todo caso no perjudica a ninguna de ellas. En juzgamiento, no se debe caer en ingenuidades. Toda parte debe tener previamente formulada su estrategia, en el marco del cumplimiento debido y responsable de su rol. Por su parte tanto la Fiscalía analizará que tan sólido es el caso y los medios probatorios que ofrece para acreditar y corroborar la imputación; y a su vez a la defensa deberá evaluar que tan débil o fuerte es la prueba de cargo y las fortalezas de su teoría del caso que plantea.

\section{Conclusiones}

a) Las convenciones probatorias son acuerdos entre las partes respecto a hechos, circunstancias o medios de prueba, toda vez que no existe controversia sobre ello y dan por ciertos; siempre que no sea el acuerdo respecto a responsabilidad penal, ni de antijuricidad, menos de culpabilidad.

b) La normatividad vigente establece que la oportunidad para plantear las convenciones probatorias son una vez conocida la acusación, debe ser formulada por escrito dentro de los 10 días de traslado de la acusación y sustentada en la audiencia preliminar de control de acusación.

c) A pesar que no existe norma expresa que lo permita, no existe prohibición, consecuentemente tampoco existe incompatibilidad para aceptar en la etapa de Juzgamiento convenciones probatorias que no hayan sido promovidas anteriormente por las partes. 
d) Podrían ser planteadas durante la etapa de juzgamiento, en un primer momento luego de conocidos los alegatos de apertura de las partes, un segundo momento luego de la admisión de nuevos medios de prueba, o puede ser durante las sesiones de actividad probatoria y finalmente aún durante la oralización de documentales (respecto a estas) y antes que concluya la fase probatoria.

e) No es ilegal y tampoco atentatorio a las competencias del Juez, la facultar de interrogar a las partes, luego de escuchar los alegatos de apertura o después de la admisión de nuevos medios de prueba, sobre la posibilidad de celebrar convenciones probatorias.

\section{Sugerencias}

a) Estando a la escasa incidencia de convenciones probatorias durante la etapa intermedia y la dispersa normatividad nacional ${ }^{34}$ como ha quedado anotado en el presente artículo, considero la necesidad de una modificación legislativa y sistematizarlo con el siguiente texto:

\section{Art. 156-A: De las convenciones probatorias:}

1. Las partes podrán acordar convenciones probatorias sobre hechos y circunstancias que tendrán por cierto sin necesidad de actuación de medio de prueba en juicio que lo acredite respecto a ello el juez de juzgamiento lo valorará como hecho no controvertido, también podrán acordar con qué actuación de medio de prueba se dará por acreditado un determinado hecho o circunstancia, siempre que no verse sobre responsabilidad penal, ni de antijuricidad, menos de culpabilidad.

2. Puede ser a instancia de parte durante la investigación preparatoria o una vez emitida la disposición de conclusión de investigación preparatoria, la cual podrán realizar reuniones preparatorios informales con la defensa

34 Artículo $156^{\circ}$ : Objeto de prueba.-

3. Las partes podrán acordar que determinada circunstancia no necesita ser probada, en cuyo caso se valorará como un hecho notorio. El acuerdo se hará constar en el acta. Artículo 350: Notificación de la acusación y objeción de los demás sujetos procesales.-

2. Los demás sujetos procesales podrán proponer los hechos que aceptan y que el Juez dará por acreditados, obviando su actuación probatoria en el Juicio. Asimismo, podrán proponer acuerdos acerca de los medios de prueba que serán necesarios para que determinados hechos se estimen probados. El Juez, sin embargo, exponiendo los motivos que lo justifiquen, podrá desvincularse de esos acuerdos; en caso contrario, si no fundamenta especialmente las razones de su rechazo, carecerá de efecto la decisión que los desestime.

Artículo $353^{\circ}$ : Contenido del auto de enjuiciamiento.-

El auto de enjuiciamiento deberá indicar, bajo sanción de nulidad:

Los medios de prueba admitidos y, de ser el caso, el ámbito de las convenciones probatorias. 
pero para finalizar el acuerdo de convención probatoria deberá dar su aceptación y conformidad el imputado asistido por su defensa y de las demás partes del proceso si están debidamente constituidas, lo cual constará en acta o en cualquier registro documental.

3. Las convenciones probatorias en un primera oportunidad podrán ser a iniciativa de cualquiera de las partes y sustentada por el fiscal en la audiencia preliminar de control de acusación ante el juez de investigación preparatoria quien emitirá la resolución de aprobación o desaprobación. Sin perjuicio de ello en la audiencia preliminar el Juez podrá preguntar a las partes si formularan convenciones probatorias.

4. En caso de aprobar la convención probatoria dejará constancia de ello en el auto de enjuiciamiento, en los términos del acuerdo, para ser tenido en cuenta por las partes y el juez de juzgamiento.

5. En caso de desaprobar la convención, deberá sustentarlo en auto motivado el cual será inimpugnable, sin perjuicio de las partes lo consideran podrán solicitar su reexamen de conformidad con el artículo $373^{\circ}$ del NCPP.

6. El Juez de juzgamiento una vez escuchados los alegatos de apertura, o de haberse admitidos nuevos medios de prueba, preguntará a las partes si existe la posibilidad de formular convenciones probatorias.

Durante el juzgamiento a iniciativa de las partes en cualquier momento antes que culmine la actividad probatoria podrán formular convenciones probatorias que sustentarán ante el juez de juzgamiento quien evaluará la razonabilidad del acuerdo para su aprobación o desaprobación, en este último caso fundamentará la necesidad de la actuación de los medios de prueba de su propósito. La resolución es irrecurrible.

\section{b) Análisis de costo y beneficios de la sugerencia legislativa}

Costos: no genera gastos al Estado, además no afecta derechos fundamentales de las partes procesales, ni se contrapone a principios reguladores de derecho procesal penal vigente.

Beneficios: El instituto procesal estando en el marco de la justicia penal negociada, queda a disposición de las partes, para que puedan utilizarla en la oportunidad que se reúne los requisitos y presupuestos, el proyecto incorpora nueva posibilidades a la negociación de las partes y reduce los obstáculos y limitaciones contenidas en el texto vigente.

La presente propuesta legislativa generará beneficios para la sociedad en su conjunto por estar orientada a una efectiva administración de justicia, marco institucional para el desarrollo del país, no generando su aplicación costos al Erario Nacional ni a los ciudadanos. 